\title{
E-commerce em 2020, um cenário de oportunidades em meio a pandemia
}

\author{
E-commerce in 2020, a scenario of opportunities amid a pandemic \\ El comercio electrónico en 2020, un escenario de oportunidades en medio de una pandemia
}

Recebido: 15/02/2021 | Revisado: 21/02/2021 | Aceito: 24/02/2021 | Publicado: 28/02/2021

Eduardo Antero Premebida

ORCID: https://orcid.org/0000-0001-5852-4569

Especialista em Gestão de Marketing Internacional pela Abracomex, Brasil

Eduardopremebida8989@gmail.com

\begin{abstract}
Resumo
O ano de 2020 foi um ano atípico em vários segmentos, nesse ano precisamos mudar hábitos, nos isolar para conter o avanço da pandemia do COVID-19, nesse momento tivemos que reaprender a viver, e com isso aspectos culturais por todo o mundo foram de alguma forma afetada, o que parecia tão afastado da realidade tornou-se a melhor alternativa para a economia, o digital foi incluído no nosso cotidiano, o setor de comercio eletrônico que cresceu $12 \%$ no primeiro semestre do ano de 2019, teve um recorde de crescimento no mesmo período analisado no ano de 2020. Nesse trabalho vamos abordar como o e-commerce foi impactado pela pandemia, e quais as expectativas para os próximos anos. A pesquisa foi desenvolvida de forma bibliográfica e quantitativa, aliando a teoria aos dados obtidos a partir de dados coletados dos últimos informativos disponibilizados pelo prêmio EBIT/Nielsen. Vamos comparar o crescimento e analisar o perfil do cliente, sendo utilizadas bases de dados das últimas edições publicadas. Nesse trabalho o objetivo foi abordar o comportamento de tomada de decisões dos millenials, por esse ser o maior player da modalidade.
\end{abstract}

Palavras-chave: Comercio eletrônico; Consumidor; Crescimento; Impacto; COVID-19.

\begin{abstract}
The year 2020 was an atypical year in several segments, this year we need to change habits, isolate ourselves to contain the progress of the COVID-19 pandemic, at that moment we had to relearn how to live, and with that cultural aspects around the world were somehow affected, what seemed so far from reality has become the best alternative for the economy, digital has been included in our daily lives, the electronic commerce sector that grew $12 \%$ in the first half of 2019 , had a record of growth in the same period analyzed in the year 2020. In this work we will address how e-commerce was impacted by the pandemic, and what are the expectations for the coming years. The research was developed in a bibliographic and quantitative way, combining theory with data obtained from data collected from the latest information available through the EBIT / Nielsen award. We will compare the growth and analyze the client's profile, using databases from the last published editions. In this work, the objective was to address the decision-making behavior of millennials, as this is the biggest player in the sport.
\end{abstract}

Keyword: E-commerce; Consumer; Growth; Impact; COVID-19.

\begin{abstract}
Resumen
El año 2020 fue un año atípico en varios segmentos, este año necesitamos cambiar hábitos, aislarnos para contener el avance de la pandemia COVID-19, en ese momento tuvimos que reaprender a vivir, y con eso aspectos culturales alrededor de la El mundo se vio afectado de alguna manera, lo que parecía tan lejos de la realidad se ha convertido en la mejor alternativa para la economía, lo digital se ha incluido en nuestra vida diaria, el sector de comercio electrónico que creció $12 \%$ en el primer semestre de 2019, tuvo un récord de crecimiento en el mismo período analizado en el año 2020. En este trabajo abordaremos cómo el comercio electrónico fue impactado por la pandemia, y cuáles son las expectativas para los próximos años. La investigación se desarrolló de forma bibliográfica y cuantitativa, combinando teoría con datos obtenidos a partir de datos recogidos de la última información disponible a través del premio EBIT / Nielsen. Compararemos el crecimiento y analizaremos el perfil del cliente, utilizando bases de datos de las últimas ediciones publicadas. En este trabajo, el objetivo fue abordar el comportamiento de toma de decisiones de los millennials, ya que este es el jugador más importante en el deporte.
\end{abstract}

Palablas clave: Comercio electrónico; Consumidor; Crecimiento; Impacto; COVID-19.

\section{Introdução}

O ano de 2020 foi um ano atípico, para muitos considerado um ano perdido, por ter sido um ano marcado por muitas dificuldades, porém, devemos analisar também as oportunidades do mundo se reinventar, mudando hábitos e costumes. O corona vírus, responsável pela pandemia do COVID-19, se espalhou pelo mundo rapidamente, deixando todos em alerta. Seu ponto 
inicial de contagio foi Wuhan, China, e em poucos meses afetou todo o mundo; em março de 2020, a OMS (Organização Mundial da Saúde) classificou a doença como pandemia mundial, nível mais alto de contágio. Por ser uma doença respiratória a circulação e a propagação do vírus são muito rápidas, o período de manifestação da doença é curto (podendo levar a óbito em poucos dias caso o paciente não seja tratado).

Entre os sintomas mais comuns estão falta de ar, febre, tosse, dor de garganta, coriza entre outros; com as novas mutações esses sintomas estão se tornando mais fortes, como medida de prevenção e enfrentamento da doença é indicado o isolamento social, até que a população adquira a chamada imunização de rebanho (referência a uma técnica de imunização em que uma determinada parcela da população se torna imune a uma doença), para que isso ocorra mais de $70 \%$ da população deve ser vacinada, porem ações de conscientização da importância do distanciamento social são as ferramentas disponíveis para frear o avanço do contagio, já que esse número ainda está longe de ser atingido. Foram feitas por todo o mundo, lockdown foi instaurado em locais com maior acumulo de pessoas, somente no Brasil, o número de casos confirmados de 03 de janeiro de 2020 à 15 de fevereiro de 2021, já chegou à 9.765 .455 casos, e 237.489 mortes em todo o território, no mundo o número já chega à marca de 108.153 .741 casos e 2.381.295 óbitos. Todos os setores, sem distinção, foram atingidos, e o comercio não seria uma exceção, mas como evitar uma crise financeira em meio uma crise sanitária?

Com base no material coletado, vamos expor sobre o perfil do consumidor, crescimento do faturamento e quais os motivos que levam o cliente a escolher essa modalidade de compra, e quais as tendências de crescimento para o próximo período.

\section{Metodologia}

O artigo tem a característica de ser quali-quantitativa, onde também é feita a busca verificar os aspectos emocionais, comportamentais e culturais, essa metodologia abrange a coleta de dados para tabular e expor em forma de gráficos as alternativas mais viáveis para um momento tão delicado, com é o caso de pandemia. Muitas vezes os métodos qualitativos podem se transformar em quantitativos por meio do emprego de questões fechadas, por exemplo, pelo emprego da Escala Likert (Pereira A.S. et al., 2018, p. 67). Conforme Yin (2015) que é uma das maiores autoridades mundiais, em relação ao estudo de caso, considera que os métodos qualitativos e quantitativos não se excluem e podem ser importantes se complementando e permitindo um melhor entendimento dos fenômenos em estudo (citado por Pereira et al., 2018, p.69).

Podemos ver a abordagem quantitativa nas Figuras 1 e 2, onde podemos verificar a expansão do setor no decorrer dos anos, e conforme sua faixa etária, a experiencia qualitativa pode ser descrita com base na Figura 3 e 4 , onde é dado um enfoque nos aspectos comportamentais dos clientes.

\section{Comercio Eletrônico}

O comércio eletrônico é em suma o processo de compra e venda de produtos por meios eletrônicos, como aplicativos móveis e Internet, tanto para o setor de varejo e compras on-line, bem como transações eletrônicas. Com o advento da globalização, o comércio não se limita mais a ir à loja física de minha preferência escolher um produto, ocorreu o fácil acesso a produtos antes que não acontecia; com um clique podemos conferir ofertas de concorrentes, escolher marcas, ver o que outros compradores falam sobre o produto que estou analisando, tudo em tempo real. Estamos em uma nova era.

Para Silvestre (2020) a palavra e-commerce é uma abreviação de electronic commerce, ou "comércio eletrônico", em uma tradução literal. Essa utilização da letra "e" para indicar algo que se dá na internet é semelhante à da feita no famoso e-mail, que significa "correio eletrônico". O e-commerce, então, se refere às transações comerciais realizadas totalmente online. Desde a escolha do produto pelo cliente, até a finalização do pedido, com o pagamento, todo o processo deve ser realizado por meios digitais. Nesse tipo de comércio, a única etapa no mundo físico é a da logística de entrega das encomendas aos compradores. De 
acordo com Parente (2000, p. 15), "O e-commerce é um formato de varejo, que pela internet, oferece produtos e serviços, facilitando para que os consumidores comprem e completem a transações por meio de um sistema eletrônico interativo".

Para Medeiros e Balduíno (2019) a evolução do marketing, que se dá por meio de 4 fases; na primeira fase, ocorreu na Revolução Industrial, com a padronização e sem personalização dos produtos comercializados, essa chamada de Marketing 1.0, caracteriza-se pelo foco na produção em massa de produtos e, consequentemente, menores custos e preços acessíveis. A segunda fase, ou marketing 2.0, os autores afirmam que os clientes possuem maior acesso à informação e passam a ter mais opções para atender a sua preferência, logo há uma preocupação maior da empresa em relação aos seus diferenciais (preço, distribuição, produto e comunicação). O marketing 3.0 traz consigo uma nova proposta que foca no lado humano do consumidor, que possui desejos, valores e objetivos, buscando satisfação a cada compra, começando a considerar comunidades digitais e a busca das empresas por se conectar com esses grupos. Quanto à fase quatro ou marketing 4.0, Kotler, Kartajaya e Setiawan (2017) apresentam um conceito que integra de forma mais efetiva os canais de marketing online e off-line, atendendo tanto vertical como horizontalmente.

Turchi (2018, p.15) indica que:

O e-commerce começou a deslanchar nos Estados Unidos por volta de 1995, com o surgimento da Amazon.com e de outras empresas pioneiras que decidiram apostar nesse novo modo de fazer negócios. (...) A chamada "bolha de oportunidade" acabou estourando no ano de 2000, na Bolsa de Valores americana, a Nasdaq, e muitas empresas e investidores que apostaram alto na web, talvez prematuramente, quebraram.

Atender essa fatia de mercado não é mais uma opção, além de aumentar a competitividade, ter uma loja virtual aumenta a alcance da empresa (praça de atuação); o meio eletrônico permite que clientes façam suas compras a qualquer momento; os custos para manter o comercio são menores; o estoque pode ser gerido mais facilmente por conta da automação; atingir o público alvo é mais fácil, pois você pode oferecer um produto especifico para a necessidade de cada cliente.

No gráfico abaixo podemos ver a evolução do e-commerce nos últimos 20 anos, como base para esse trabalho vamos nos prender no primeiro semestre, para termos um melhor aproveitamento, para um trabalho futuro haverá uma abordagem anual.

Figura 1 - Retirada do Webshoppers (2020). 42 Edição. Edição Free. Ebit/Nielsen. Pg. 10.

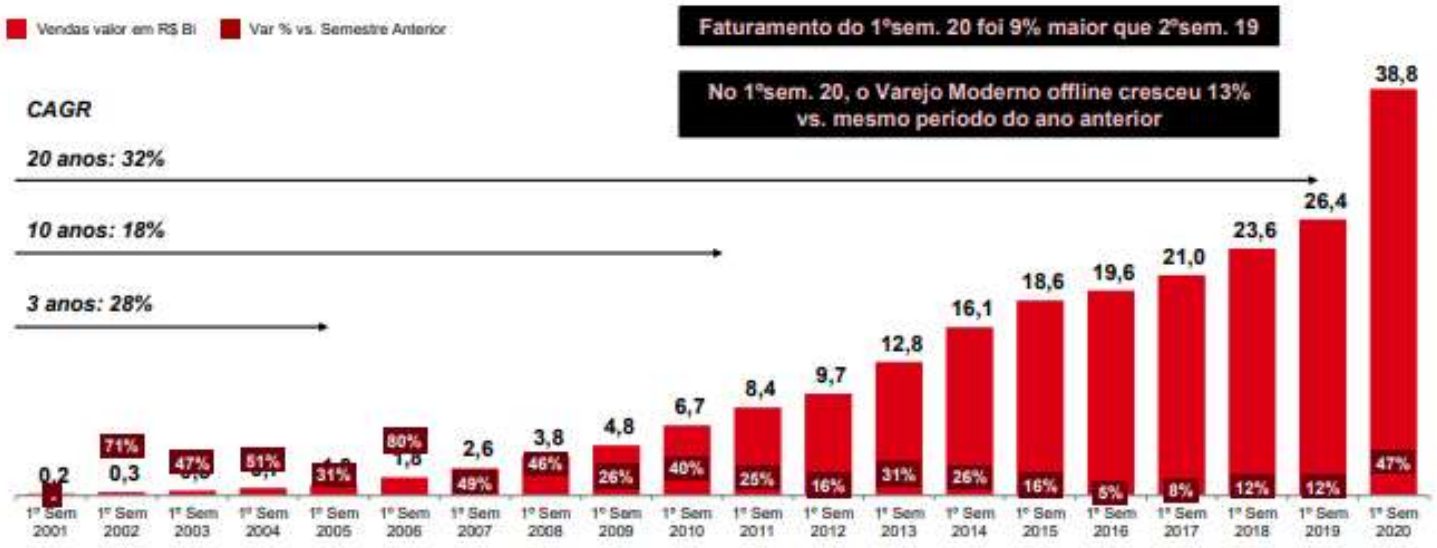

Fonte: Autores.

Como podemos ver, o crescimento no primeiro semestre do último ano teve um incremento nas vendas de $47 \% \mathrm{em}$ relação ao mesmo período analisado no ano anterior, a pandemia teve impacto nesse resultado, já que o crescimento e o faturamento são muito maiores que os resultados antes conquistados. 
O comercio eletrônico deve ser entendido como um novo paradigma a ser quebrado na maioria das empresas. É comum ver empresas que poderiam estar se beneficiando consideravelmente do e-commerce não investirem na área por acharem que seus produtos ou negócios não podem ser vendidos online. Eles só mudam esse pensamento quando surge um forte concorrente online mostrando sim, era possível. Torres (2018, p. 50)

\section{Migração do Consumidor: do Físico ao Digital}

Para Kotler (2017, p. 69) o estágio inicial de interação entre empresas e consumidores, o marketing tradicional desempenha papel importante ao promover a consciência e o interesse. À medida que a interação avança e os clientes exigem relacionamentos mais próximos com as empresas, aumenta a importância do marketing digital.

A interação entre os meios de compra deve ser mantidos, um apoiando o outro, de forma que exista uma correlação entre eles, uma forma de estimulo pode ser mantida com a finalidade de incentivar a compra virtual, um exemplo desse modelo são as compras sociais em que o cliente usa um boneco (avatar com suas especificações físicas) virtual para escolher suas peças de roupa na loja de sua preferência.

Para Kotler e Armstrong (2015, p. 195) as empresas estão utilizando uma serie de abordagens digitais e sociais com o objetivo de alcançar os clientes organizacionais e gerenciar os relacionamentos com eles em qualquer lugar, a qualquer hora. Como não podemos parar nossos concorrentes, nem o mercado e muito menos o relógio da evolução digital, necessitamos de um processo de melhoria continua das nossas estratégias digitais. Necessitamos implementar um processo que inclua aprendizagem, analise e alinhamento e garanta que nossa identidade e estratégias digitais evoluem constantemente. Torres (2018, p. 294)

\section{Definição do Mercado Consumidor}

O mercado consumidor é o termo para delimitar a parcela dos clientes que movimentam o segmento, o e-commerce era predominante o perfil de clientes acima de 35 anos, como podemos ver na figura abaixo.

Figura 2 - Retirada do Webshoppers (2020). 39 Edição. Edição Free. Ebit/Nielsen. Pg. 28.

\section{PERFIL DO CONSUMIDOR ONLINE - IDADE}

\begin{tabular}{|l|c|c|c|}
\hline FADA ETAPIA & 2016 & 2017 & 2018 \\
\hline ATÉ 24 ANOS & $8 \%$ & $9 \%$ & $9 \%$ \\
\hline ENTRE 25 E 34 ANOS & $23 \%$ & $24 \%$ & $24 \%$ \\
\hline ENTRE 35 E 49 ANOS & $35 \%$ & $37 \%$ & $37 \%$ \\
\hline ACIMA DE 50 ANOS & $34 \%$ & $30 \%$ & $29 \%$ \\
\hline IDADE MÉDIA (ANOS) & 43,4 & 42,2 & 42,1 \\
\hline
\end{tabular}

Fonte: Autores.

Além da idade outros parâmetros devem ser levados em consideração, tais como a região que o consumidor reside influencia muito na decisão de compra. 
Com base na idade média dos clientes, temos maiores concentrações a partir de 35 anos, que são pertencentes da geração Y, também chamados como millenials (nascidos entre os anos de 1980 a 1994), e o que esse perfil de cliente procura? Segundo Junqueira (2020) a geração Y representam 54\% das compras online; 22\% usa aplicativos para comprar mantimentos; $63 \%$ concluem as transações em seus smartphones; $40 \%$ analisam avaliações e depoimentos online antes de comprar qualquer produto. O Comportamento desse perfil de cliente está diretamente relacionado com as experiencias dos produtos, reforçando a ideia de Turchi (2018, p. 210) de que o Brasil é um dos países com maior número de internautas. A maior parte desses públicos navega de casa ou do trabalho e está observando a comunicação das empresas e seus produtos, trocando ideias, jogando, "blogando", pesquisando, colaborando e influenciando o consumo uns dos outros.

Por conta da pandemia do corona vírus, os hábitos e comportamentos mudaram, um deles foi o distanciamento social, com isso o delivery ganhou mais destaque entre os consumidores brasileiros, na figura abaixo podemos verificar que em 2020 o fator determinante na compra por aplicativos se dá por conta de "não precisar sair de casa".

Figura 3 - Retirada do Webshoppers (2020). 42 Edição. Edição Free. Ebit/Nielsen. Pg. 28.

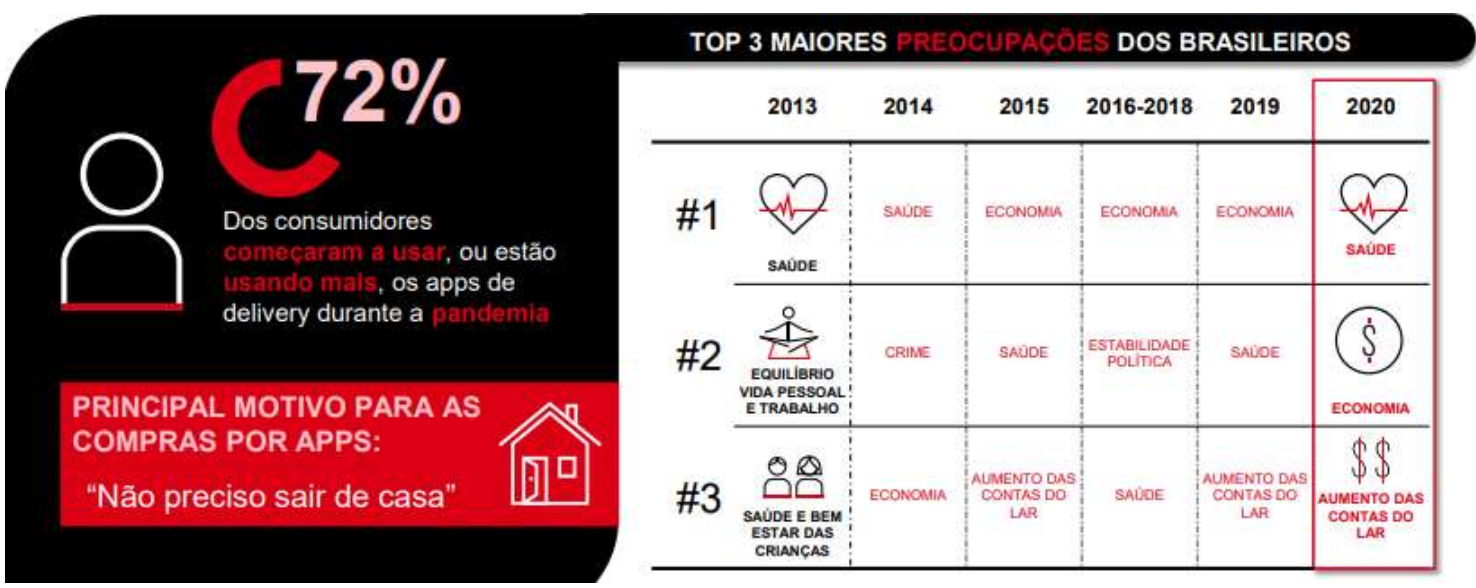

Fonte: Autores.

Nessa modalidade de compra, podemos ver que a em todos os períodos analisados a saúde é uma das 3 maiores preocupações que o brasileiro tem, sendo que nos anos 2013, 2014 e 2020, essa ocupou o primeiro lugar no ranking. Levando em consideração o perfil de cliente anteriormente traçado, podemos verificar que o mercado consumidor pesquisou antes de fazer a compra, viabilizando custos e benefícios da compra na modalidade digital.

Sant'anna (2017 p. 231) nos permite entender melhor o envolvimento do consumidor, onde define que os produtos são, na verdade, representações tangíveis de necessidades, sentimentos, emoções e desejos que habitam as profundezas de nosso ser. Um produto ou uma marca nada mais são do que uma ponte, uma espécie de elo entre o "estado atual" e o "estado desejado". O ato da compra e o posterior consumo, em última análise, representam a redução desse estado de tensão. A sensação de prazer ou satisfação será sempre, por definição, temporária.

$\mathrm{Na}$ economia digital, os clientes estão empoderados e tornou-se mais fácil para eles avaliar e até esmiuçar a promessa de posicionamento da marca de qualquer empresa. Com essa transparência (graças a ascensão da mídia social), as marcas já não podem fazer promessas falsas, não verificáveis. As empresas podem se posicionar como qualquer coisa, mas, a menos que exista um consenso baseado na comunidade, o posicionamento não significa nada mais que dissimulação corporativa. Kotler (2017, p. 65-66) 


\section{Influência da Pandemia no E-commerce}

Aqui no Brasil, o distanciamento social ganhou intensidade no mês de março, quando a OMS declarou pandemia mundial. Portanto, estamos há aproximadamente um ano convivendo com uma rotina de muito mais tempo dentro de casa de modo que comprar pela internet virou um hábito. Com esse cenário, o setor de compras pela internet teve um incremento nas vendas, antes setores que eram apenas presenciais, ou off-lines, passaram a ter serviços oferecidos em plataformas de compras digitais. Para Kotler (2017, p. 61), essas tecnologias ajudam a desenvolver vários setores na economia, como varejo (comercio eletrônico), transportes (veículos automatizados), educação (cursos abertos on-line), saúde (prontuários eletrônicos e medicina personalizada), bem como interações sociais (redes sociais). Entretanto, muitas das mesmas tecnologias que impelem a economia digital também estão abalando setores-chaves e perturbando empresas tradicionais.

Figura 4 - Retirada do Webshoppers (2020). 42 Edição. Edição Free. Ebit/Nielsen. Pg. 32.

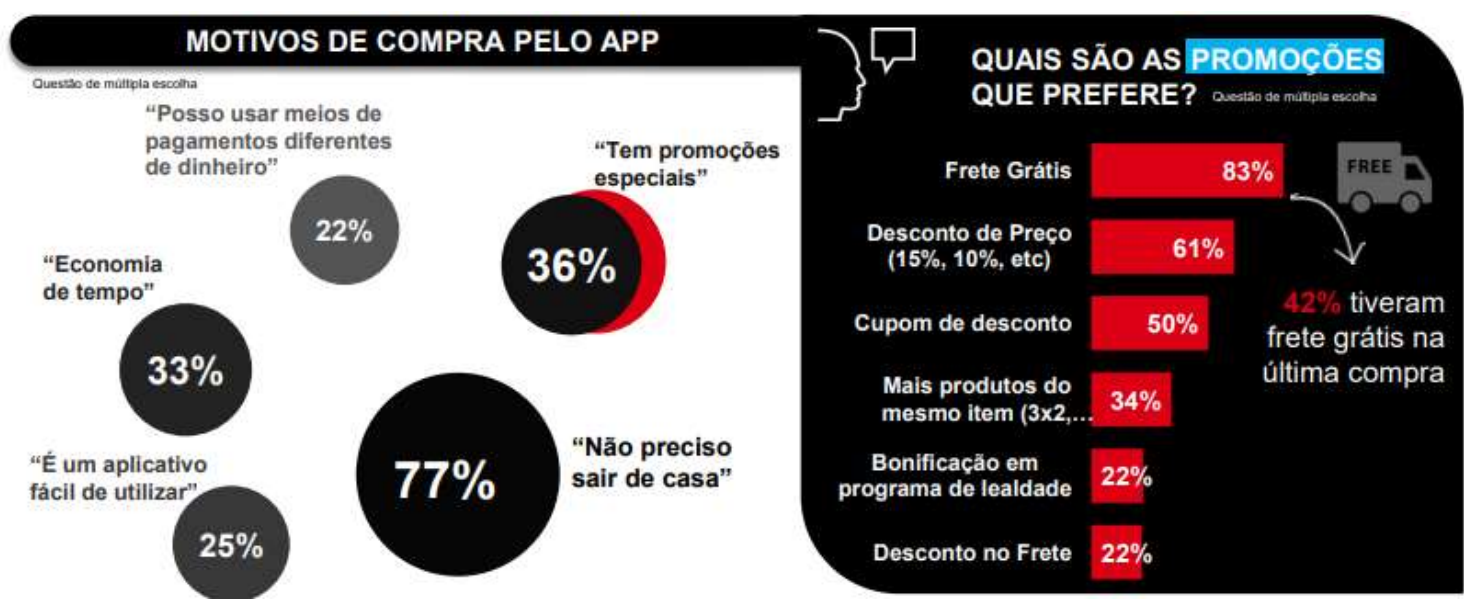

Fonte: Autores.

Sobre as motivações dos compradores digitais, 77\% deles foi influenciado por "não precisar sair de casa"; seguido por motivos econômicos, com 36\% o fator de "ter promoções especiais" e 33\% "economia de tempo". Com relação as promoções, o fator que mais causa impacto nos consumidores é o frete grátis, e o que menos impacta é o desconto no frete, ou seja, a entrega é fator determinante na hora da escolha do fornecedor.

Os constantes avanços tecnológicos, o acesso móvel, os aplicativos, a inclusão digital e o crescimento da internet, são fatores que tendem a fortalecer esta nova modalidade de compra. As pessoas buscam por comodidade, segurança, bons produtos, preços e marcas preocupadas com a satisfação do cliente. Com o passar do tempo, o receio de comprar pela internet foi sendo deixado de lado e o consumidor levou o desejo de ser bem atendido nas lojas físicas para o universo digital. Rez (2016, p. 37)

\section{Considerações Finais}

O presente trabalho, visou demonstrar o perfil do e-commerce, em meio ao avanço dos métodos de contenção do vírus do COVID-19, possivelmente um dos setores que mais cresceu para tentar frear o contagio da doença, possivelmente logo todos os setores voltaram a funcionar com medidas de biossegurança ainda reforçadas, pois não teremos a mesma interação que possuíamos antes, até por conta de uma mudança comportamental e cultural que foi desencadeada por conta da pandemia.

Podemos observar nesse trabalho que o perfil do consumidor tem mudado com frequência, com o passar dos anos o comercio eletrônico tem ganhado mais e mais adeptos, o que antes era apenas uma forma de apoio, hoje já não pode mais ser visto dessa maneira, pois o consumidor quer a cada momento estar mais conectado a marca. 
Até que o "antigo normal" (como é denominado o período sem pandemia) volte, com o avanço das pesquisas, e campanhas de vacinação, essa doença deve ser controlada em alguns meses, enquanto isso o e-commerce deve continuar crescendo, abrangendo cada vez mais setores que antes eram exclusivos de lojas físicas. Essa pode não ser a maneira mais eficaz e eficiente de conquistar clientes, porém, é uma forma de ganhar espaço em mercado existente, ainda não sendo possível saber o tamanho dessa nova demanda gerada. (Kim \& Mauborgne, 2015)

Ao longo desse trabalho conseguimos responder perguntas como: Para quem vendemos; quanto; e o que motiva esses clientes. Reconhecendo o perfil do consumidor do e-commerce, como também o padrão de compra e suas motivações. Um novo estudo pode ser feito no futuro, observando vantagens e desvantagens do comercio físico perante ao digital, onde o autor pode verificar o impacto da migração de sistemas, e quais os aspectos culturais e comportamentais que impedem que um segmento exclua o outro.

Outra sugestão para futuro trabalho, é fazer uma análise de crescimento anual do segmento alimentício, onde os fornecedores foram "obrigados" a migrar para plataformas de delivery.

\section{Referencias}

de Mendonça, H. G. (2016). Comércio eletrônico. Revista Inovação, Projetos e Tecnologias - IPTEC, 4 (2), 240 - 251.

Junqueira, G. (2020) Geração Z e Millennials, entenda as diferenças e o impacto no seu negócio. Obtido em: https://www.infovarejo.com.br/geracao-Z-emillennials-entenda-as-diferencas-e-o-impacto-no-seu-negocio/

Kim, W. C. \& Mauborgne, R. (2014) Estratégia do oceano azul, edição ampliada: como criar espaço de mercado incontestado e tornar a concorrência irrelevante. Harvard business review Press.

Kotler, P., \& Armstrong, G. (2015) Princípios de Marketing. (15a ed.), Pearson Prentice Hall. 780p.

Kotler, P., Kartajaya, H, \& Setiawan, I. (2017) Marketing 4.0: Do tradicional ao digital. Ivo Korytovski. Sextante.

Medeiros, A. C. Balduíno, \& Maria A. C (2019). O marketing 4.0 e a importância da comunicação com o novo consumidor nas redes sociais. Revista Científica Multidisciplinar Núcleo do Conhecimento, (9a ed.), 1, 160-175.

Nascimento, I. S. S (2019). O efeito da comunicação em mídias digitais sobre o comportamento do consumidor: um estudo no mercado de food delivery. 58 f. Trabalho de Conclusão de Curso (Graduação em Administração) - Universidade Federal do Ceará, Faculdade de Economia, Administração, Atuária e Contabilidade, Fortaleza.

Parente, J. (2000). Varejo no Brasil: gestão e estratégia. Editora Atlas.

Pereira, A. S., et al. (2018). Metodologia da pesquisa científica. UFSM. https://repositorio.ufsm.br/bitstream/handle/1/15824/Lic_Computacao_MetodologiaPesquisa-Cientifica.pdf?sequence $=1$

Rez, R. (2017). Marketing de conteúdo: a moeda do século XXI. DVS Editora.

Silvestre, L. (2020) O que é e-commerce: para que serve e como funciona? Obtido em: https://www.nuvemshop.com.br/blog/o-que-e-ecommerce/

Torres, C. (2018). A bíblia do marketing digital: tudo o que você queria saber sobre marketing e publicidade na internet e não tinha a quem perguntar. Novatec Editora.4

Turchi, S. R. (2018). Estratégia de marketing digital e e-commerce, (2a ed.).

Webshoppers (2019). 39 Edição. Edição Free. Ebit/Nielsen

Webshoppers (2020). 42 Edição. Edição Free. Ebit/Nielsen

World Health Organizacion: Brasil (2021). https://covid19.who.int/region/amro/country/br 